\title{
Directional Dispersion Effect of Thin and Short Fibers on Performance of High Ductile Mortar
}

\author{
Tek Raj Gyawali* \\ Department of Science and Technology, Pokhara University, Nepal
}

Submission: February 07, 2020; Published: July 06, 2020

*Corresponding author: Tek Raj Gyawali, Department of Science and Technology, Pokhara University, Nepal

\begin{abstract}
The plain cement mortar is weak in flexural and ductility behavior. If the thin and short synthetic fibers, like Poly Vinyl Alcohol (PVA) fibers, are uniformly distributed and well coated with mortar, it enhances the both flexural and ductility. The directional dispersion effect of PVA fibers was investigated on the flexural and deflection behaviors of High Ductile Mortar (HDM). In the first attempt, 2-dimensional dispersion effect was studied with the HDM beams of different depths. And in the second, the $50 \mathrm{~mm}$ beam mold was cast with 1 layer (50 mm depth of layer) and 5 layers ( $10 \mathrm{~mm}$ depth of each layer). The flexural strength of $12 \mathrm{~mm}$ deep beams increased by about $35 \%$ than that from $48 \mathrm{~mm}$ beams, with an increase of deflection by about $800 \%$. The flexural strength of five layers casting $(10 \mathrm{~mm}$ each) beams was increased by about $36 \%$ than from the one-layer $(50 \mathrm{~mm})$ casting, with an increase in the deflection by about $410 \%$. The analytical model satisfied the experimental results. The 2-dimensional dispersed fibers enhanced the both flexural and deflection behaviors of HDM. It is recommended not to use the fibers of length not less than the thickness of the casting layer. This result was used for the manufacture of lightweight composite panels.
\end{abstract}

Keywords: High Ductile Mortar (HDM); Poly Vinyl Alcohol (PVA) fibers; 2-Dimensional Dispersion; 3-Dimensional Dispersion; Flexural Strength; Deflection Behavior

\section{Introduction}

The concrete is considered as one of the most difficult materials to handle, because it is the mixture of different sizes materials like water, cement and aggregates [1]. Different modern types of concretes like self-compacting concrete (SCC) [2-4] and ultra-high strength concretes [5] have already been developed. Steel fiber is the discrete, short length of steel with its aspect ratio (ratio of the length to diameter) ranging from 20 to 100 [6]. Steel Fiber reinforced concrete (SFRC) is also considered as the prestigious construction material with its high flexural strength and ductility. The various research and developments have been carried out with FRC materials since the early 1960's for its wide range of practical applications [7]. American Concrete Institute (ACI) had listed the 5 methods of adding fibre materials while mixing SFRC [8].

It has, however, indicated that the fibres should be added to a fluid mix, either as the last stage of mixing or added to the mixer with the aggregates [9]. The effect of mixing procedure on the properties of fibre reinforced concrete, especially with the feeding sequence of ingredients into the mixer, was studied by Bartos and Hoy [10-12]. They claimed that ordinary commercially available concrete mixers may not give the better quality of mixed FRC $[11,12]$. Japan Concrete Institute [13] has recommended that the fiber materials to be fed after the completion of the mixing of the plain concrete.

Synthetic fibres are considered as an inexpensive reinforcement, with no corrosion, for concrete. Victor Li. first introduced Engineered Cementitious Composites (ECC) in early 1990s [14-16]. Poly Vinyl Alcohol (PVA) fibres were developed by the time. PVA fibres have high tenacity, high modulus, low elongation, light weight, good resistance against chemicals (alkaline), good adhesion to cement matrix [17]. Gong and Zhang found that using high performance fibre-reinforced cementitious composite (HPFRCC) materials, instead of normal concrete in RC frames, increased the ultimate load, ultimate deflection, ductility ratio, and plastic hinge characteristics of the frames Pang et al. [18] determined the effect of the fly ash on the ultimate tensile stress and strain of the high ductility cementitious composites [19]. Li and Xu proposed the bending properties and toughness evaluation method of high toughness cementitious composites [20]. The impact resistances of high-performance fiber reinforced composites were studied by Wang et al. [21] and Zhang et al. [22].

Various attempts were made by Gyawali to enhance the flexural and deflection behavior of High Ductile Mortar (HDM) with PolyVinyl Alcohol (PVA) fibers. These include dispersion method of PVA fibers and mixing in mortar [23], development of High Ductile Mortar mixing method [24], effect of sizes and contents of fibers [25] and different types of sand and mixing process [26]. The author hereby has studied the directional dispersion effect of thin and short PVA fibers on flexural strength and deflection of HDM. 


\section{Objective}

The main aim is to investigate the directional dispersion effect of thin and short Poly-Vinyl Alcohol (PVA) fibers on flexural and deflection behavior of High Ductile Mortar (HDM). Its specific objective is to determine the effect of PVA fibers on flexural strength and deflection when they are made to disperse in 2-dimensional and 3-dimensional directions with the following two casting methods.

a) Casting the beam specimens of varying depth

b) Casting the same depth of beam with one layer of casting and 5 layers of casting

\section{Materials and Procedure}

Since the target of this experimental work was to check the effect of directional dispersion of thin and short fibers, type of PVA fiber and its content, mix proportion of HDM as well as mixing procedure were kept the same.

\section{Type and characteristics of PVA fiber}

REC15 type PVA fiber was used in all series of experimental works. Its characteristics are given in Table 1.

Table 1: Properties of PVA fiber used in experimental investigation.

\begin{tabular}{|c|c|}
\hline Parameters & Characteristics \\
\hline Fiber Type & REC15 \\
\hline Diameter (mm) & 0.04 \\
\hline Length (mm) & 12 \\
\hline Specific gravity & 1.3 \\
\hline Tensile strength (MPa) & 1600 \\
\hline Young's modulus (GPa) & 41 \\
\hline Fiber Elongation (\%) & 6 \\
\hline
\end{tabular}

\section{Mix proportion}

The water cement ratio (W/C) was $30 \%$ with unit cement content (C) of $1000 \mathrm{~kg} / \mathrm{m}^{3}$ and unit content of water (W) of 300 $\mathrm{kg} / \mathrm{m}^{3}$. The content of PVA fiber was $2 \%$ by volume. $1.0 \%$ of super plasticizer (by weight of cement) and $0.3 \%$ of viscosity agent (by weight of water) were used to enhance the workability and viscosity of mortar.

\section{Mixing procedure}

The HDM mixing method was used in all series of experimental work. Mixing was carried out in a mortar mixer with 6 liters per each batch. The viscosity agent was pre-mixed with cement in bucket by small scoop. The dry mixing of sand and cement was carried out for 30 seconds. Then, the first part of the water was poured into the mixer and wet mixing was carried out for 2 minutes. When pouring the water, the mixer was run with low speed. After finishing the charging of water, the mixing was done with high speed for one minute. Then, PVA fibers were charged into the mixer while mixing on low speed. After finishing the charging of fibers, the mixing was done in high speed for one minute. Finally, the remaining water was added and then mixing was done for further one minute.

\section{Specimens casting and test methods}

The workability and the viscosity of the HDM mortar were found same in all cases. PVA fibers were uniformly distributed, without any clumps, and firmly coated by the mortar. The average table flow value of each HDM was more than $150 \mathrm{~mm}$. It was the workability requirement of the fresh HDM for the easiness of casting. Three specimens of small beams were produced in all series of experiments. The specimens were initially air cured for 24 hours, followed by the water tank curing until the test day.

\section{Test specimens of varying depth}

Three wooden (plywood) beam molds of each depth of $6 \mathrm{~mm}$, $12 \mathrm{~mm}, 20 \mathrm{~mm}, 30 \mathrm{~mm}$ and $48 \mathrm{~mm}$ were prepared in these series of tests. The length $(400 \mathrm{~mm})$ and width $(100 \mathrm{~mm})$ were same. All specimens were cast with the same quality of the HDM mixed at the same time under the similar environmental conditions. The air curing and water curing of all specimens were carried out under the similar conditions.

\section{Varying depth of casting layer}

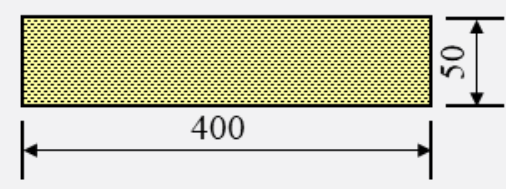

1 Layer Method

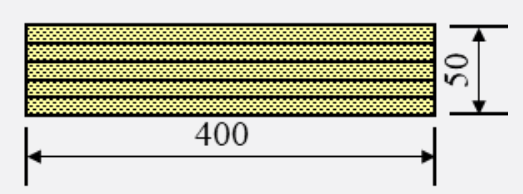

5 Layers Method

Figure 1: Casting Method of Fiber Mortar into Molds.

The standard steel molds with sizes of $400 \mathrm{~mm} \times 100 \mathrm{~mm} \times$ $50 \mathrm{~mm}$ (length $\times$ width $\times$ depth) were used in this method of casting. Casting of fiber mortar into the mold was done in 1 layer and 5 layers, as shown in Figure 1. In 1-layer casting method, the whole mold was cast at once. It was done for maintaining the directional dispersion of fibers in 3-dimensions. In 5 layers casting method, the depth of each cast layer was $10 \mathrm{~mm}$ to make the dispersion of fibers in 2-dimensions. It is due to the depth of each layer $(10 \mathrm{~mm})$ 
being less than the length of fiber $(12 \mathrm{~mm})$. Three specimens were produced from each casting method. The curing method was the same to those cast with varying depth specimens.

Since this investigation was for the comparative study, the bending tests were done in 7 days age. It was done with 4-point loading method, shown in Figure 2. Gauges were set at the exact center of the depth, on both sides, to measure the deflection. The average values of the deflection from the both sides were taken for the study.

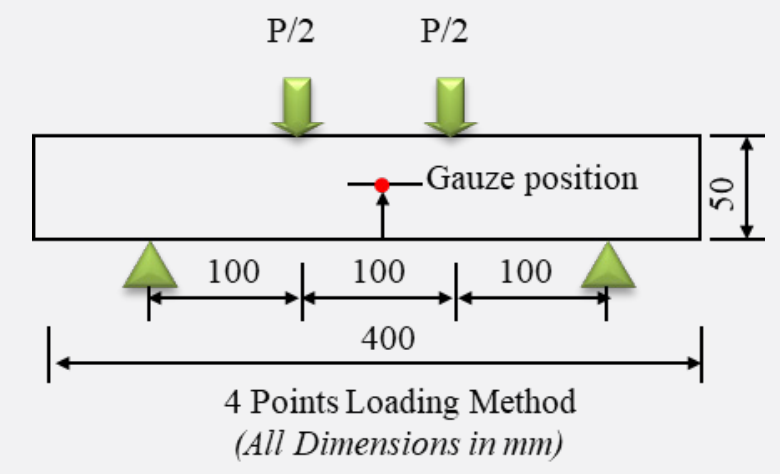

Figure 2: Bending Test Method.

\section{Test Results}

The data of load vs. deflection values were recorded from the bending test of each specimen. The flexural stress was calculated from the recorded load. The trend of flexural stress-deflection relationship was studied in general. The maximum flexural stress was considered as the flexural strength and the deflection value at this point as deflection.

\section{Results on test specimens of varying depth}

Average seven days flexural stress-deflection relationships of test specimens with a depth of $6 \mathrm{~mm}, 12 \mathrm{~mm}, 20 \mathrm{~mm}, 30 \mathrm{~mm}$ and $48 \mathrm{~mm}$ are shown in Figure 3. The $12 \mathrm{~mm}$ beam showed more deflection before the failure. It was due to 2-dimensional distribution of PVA fibers. It is assumed that, 2-dimensional distribution of PVA fibers increased the probability of having the direction of fibers in 1- dimensional distribution (longitudinal direction of the beam) to resist the flexural stress as well as strengthening the bridging work to resist the widening of micro cracks. The results obtained for the case of $20 \mathrm{~mm}$ and $30 \mathrm{~mm}$ specimens were in-between. Moreover, numbers of micro-cracks before the failure were more on the thin beam than in the thicker one. However, the result was different with $6 \mathrm{~mm}$ beam which gave the least flexural strength. Moreover, the flexural stress was fluctuating at every point of loading. It is assumed that the depth of the beam was not sufficient with respect to the length of the fiber $(12 \mathrm{~mm}$ ) used. Figure 4 gives the 7 days flexural strength of the varying depth of beams.

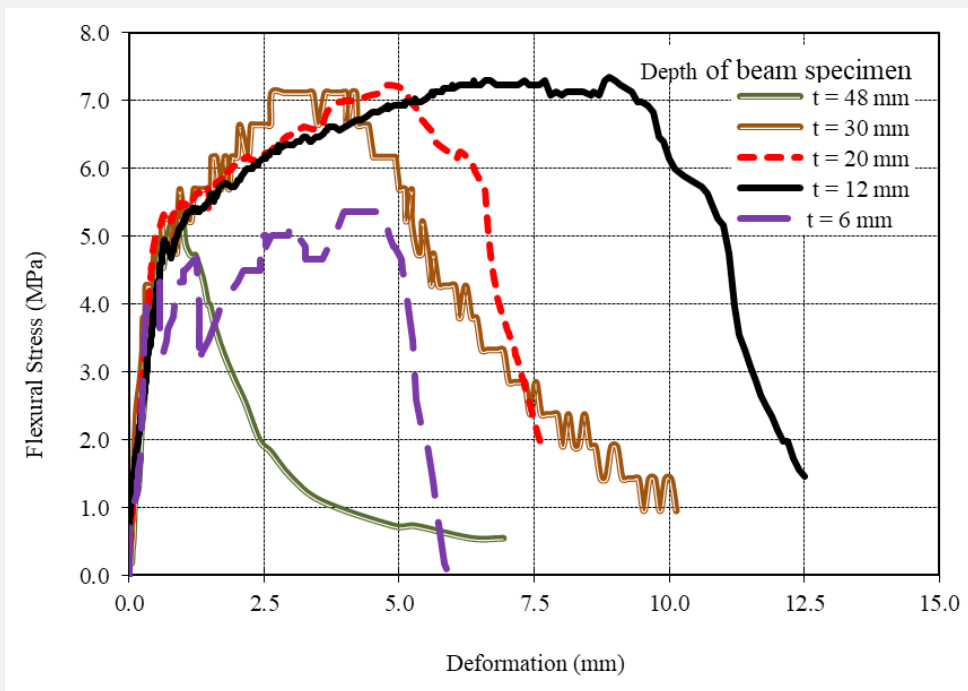

Figure 3: Flexural Stress-Deflection relationships on varying depth of Beam Specimens. 


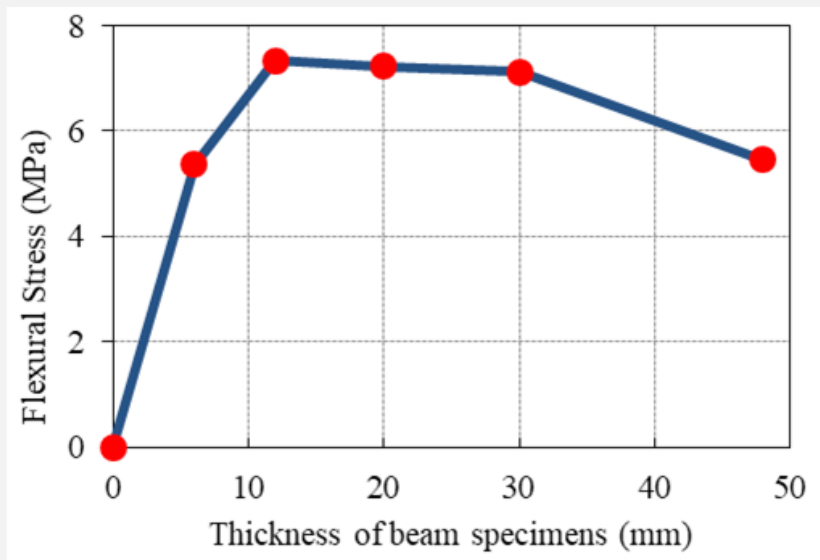

Figure 4: Seven days Flexural strength of Beams with varying Depth

The flexural strength of the $12 \mathrm{~mm}$ beam was the maximum (7.34MPa) followed by those of $20 \mathrm{~mm}(7.23 \mathrm{MPa}), 30 \mathrm{~mm}$ (7.12MPa) and $48 \mathrm{~mm}$ beams (5.45MPa). The increase in flexural strength of the $12 \mathrm{~mm}$ beam was about $35 \%$ than that of the $48 \mathrm{~mm}$ beam. The trend of decreasing of flexural strength while increasing the depth from $12 \mathrm{~mm}$ to $30 \mathrm{~mm}$ was slight, but steep from 30 $\mathrm{mm}$ to $48 \mathrm{~mm}$. The overall trend of decrease in flexural strength, while increasing the depth, was found in the tentative parabolic form. With exception, the flexural strength of $6 \mathrm{~mm}$ beam was the minimum (5.36MPa).

Figure 5 shows the deflection values of beams, with varying depth, on their maximum flexural strength capacity. The deflection value of $12 \mathrm{~mm}$ beam was the maximum $(8.99 \mathrm{~mm})$, following by those of $20 \mathrm{~mm}(4.77 \mathrm{~mm}), 30 \mathrm{~mm}(2.64 \mathrm{~mm})$ and $48 \mathrm{~mm}(0.98 \mathrm{~mm})$ beams. The deflection of $12 \mathrm{~mm}$ beam was about $800 \%$ more than that of the $48 \mathrm{~mm}$ beam. Unlike the flexural strength, the decrease of deflection of $12 \mathrm{~mm}$ to $20 \mathrm{~mm}$ beams was steeper than in the range of $20 \mathrm{~mm}$ to $30 \mathrm{~mm}$ beams. The decrease trend from $30 \mathrm{~mm}$ to $48 \mathrm{~mm}$ beams was slight. The deflection value of $6 \mathrm{~mm}$ beam was $4.2 \mathrm{~mm}$, less than that of the $12 \mathrm{~mm}$ beams. The trend of the deflection curve was linear with the thickness up to $12 \mathrm{~mm}$ (equal to the length of fiber). It was tentative exponential decay with the thickness from $12 \mathrm{~mm}$ upward.

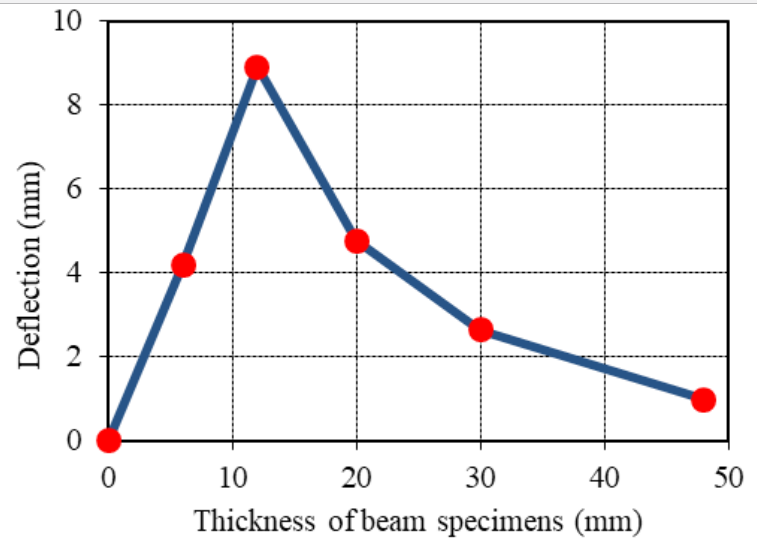

Figure 5: Deflection values of Beams with varying Depth on their Maximum Flexural Strength.

\section{Results on varying depth of casting layer}

Figure 6 gives the relationship of stress-deflection curve on casting methods of 1 layer and 5 layers of the same depth of $50 \mathrm{~mm}$ beam mold. The flexural strength of one-layer casting $(50 \mathrm{~mm})$ was only $4.76 \mathrm{MPa}$ with its deflection value of $1.05 \mathrm{~mm}$.
The flexural strength of 5 layers casing $(10 \mathrm{~mm})$ was $7.41 \mathrm{MPa}$ with its deflection value of $4.2 \mathrm{~mm}$. Increase in flexural strength and deflection of 5 layers casting was about $36 \%$ and $410 \%$ respectively than one-layer casting. The fibers of $12 \mathrm{~mm}$ length were assumed to be distributed randomly (3-dimensions) in 1-layer casting and in 2-dimensions in 5 layers. 


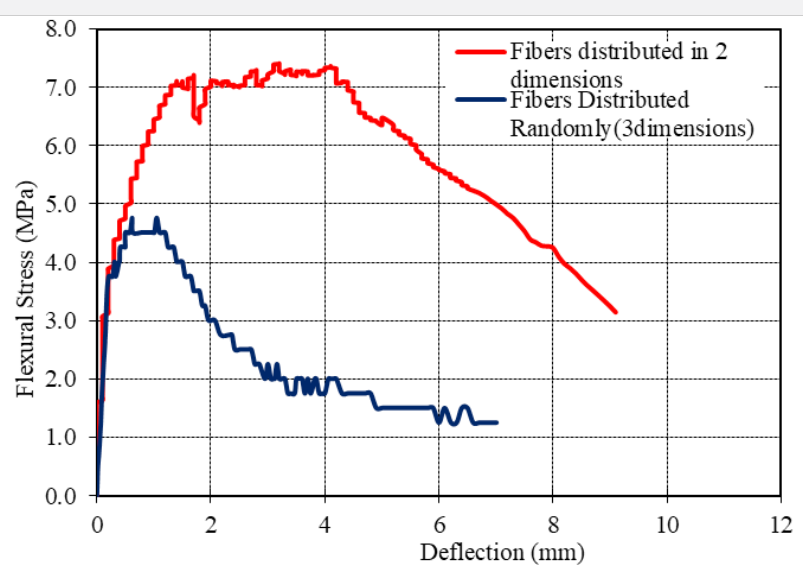

Figure 6: Stress-deflection relationships on varying Depth of Casting Layers.

\section{Analysis and Discussions}

The analytical model was developed for the both flexural strength and deflection in a variation of the thickness of the specimens. Equation 1 gives the empirical formula for the relation of the flexural strength with thickness.

$$
f_{b}=k_{1} \sin \left(k_{2} t^{k_{3}}\right)
$$

Here, $\mathrm{f}_{\mathrm{b}}$ is the flexural strength in MPa and $\mathrm{t}$ is the thickness of beam in $\mathrm{mm}$. The constant $\mathrm{k} \_1$ depends upon the type and the percentage of fiber. The constants $k_{2}$ and $k_{3}$ depend upon the direction orientation of fibers and act as the reduction factor of thickness to match with the exact value of $\mathrm{f}_{\mathrm{b}}$ in MPa.

Equation 2 gives the empirical formula for the relation of the deflection with thickness.

$$
\delta=c_{1} t(\text { for } 0 \leq t<\varphi)
$$

$$
\delta=c_{2} e^{\left(-c_{3} t^{c 4}\right)}\left(\text { for } t^{3} \geq \varphi\right)
$$

Here, $\delta$, t and $\Phi$ are the deflection, thickness of the beam and length of fiber in $\mathrm{mm}$, respectively. In equation 2(a), the constant $c_{1}$ depends upon the type and percentage of fiber and acts as the reduction factor for the thickness. In equation (2b), $c_{2}$ depends upon the type and percentage of fiber. The constants $c_{3}$ and $c_{4}$ are for the direction orientation and the reduction factor of thickness.

Figure 7 compares the analytical and the experimental data. Values of $\mathrm{k}_{1}, \mathrm{k}_{2}$ and $\mathrm{k}_{3}$ are $7.4,0.45$ and 0.43 respectively. The analytical result satisfactorily fits with the experimental results. However, the experimental data of $6 \mathrm{~mm}$ beam are less than the analytical result. Furthermore, experimental data from the second series experiment are also plotted in the graph. The data for onelayer casting $(50 \mathrm{~mm})$ fits well with the analytical result. However, the data of 5 layers casting $(10 \mathrm{~mm}$ each) are more than that of analytical result and a little bit more than that of the $12 \mathrm{~mm}$ beam.

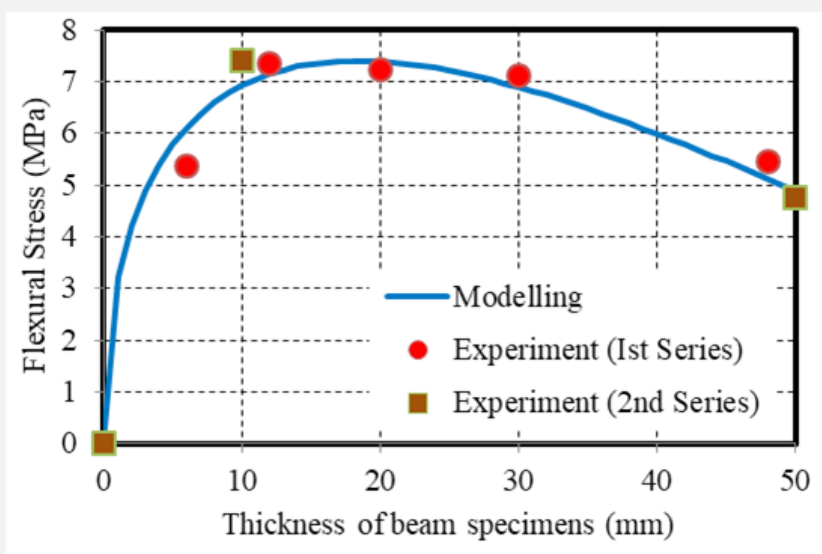

Figure 7: Comparison between Analytical Model and experiment results for Flexural Strength. 
The comparison of analytical model and experimental results for the deflection is shown in Figure 8. The values of $c_{1}, c_{2}, c_{3}$ and $c_{4}$ are $0.74,64,0.5$ and 0.55 respectively. The analytical curve fits to the experimental data satisfactorily. The test data of $50 \mathrm{~mm}$ beam (one-layer casting), from the second series experiment, perfectly fit with the analytical curve. However, the test data of 5 layers casting (10mm each) are far below than that of analytical results. With the observation of bending tests followed by the study of the pattern of stress-strain curve, flexural strength and deflection; the author hereby recommends that the thickness of any HDM specimen should not be less than the length of PVA fiber for HDM.

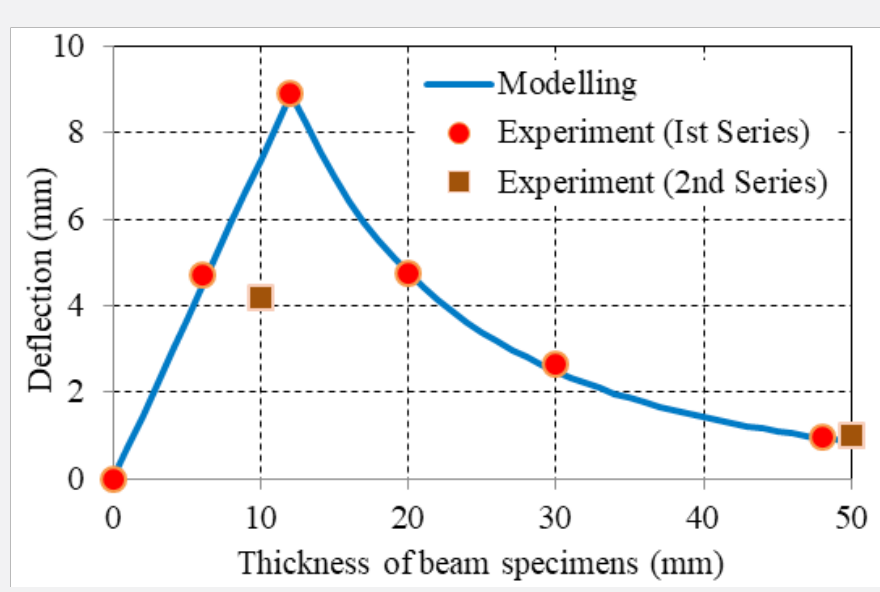

Figure 8: Comparison between Analytical Model and Experiment results for Deflection.

From this study, it was understood that the directional dispersion effect of small and thin PVA fibers is vitally important for enhancing the both flexural and deflection behaviors of HDM. Two-dimensional distribution of PVA fibers enhances the both flexural and deflection behavior of HDM. In practical application, it is possible to make the 2-dimension dispersion of short and thin fibers by producing the high flowable HDM. It may give its characteristics of self-flowing, self-compacting and self-leveling while pouring to any mold or formwork from any fixed position.

\section{Conclusion}

The directional dispersion effect of short and thin PVA fibers $(\varphi 40 \mu \mathrm{m} \times 12 \mathrm{~mm})$ was experimentally studied by taking two major parameters of specimen casting methods. In the first series of experiment, the flexural strength of $12 \mathrm{~mm}$ beam was the maximum (7.34 $\mathrm{MPa}$ ) with its respective deflection value of $8.90 \mathrm{~mm}$. The flexural strength of $48 \mathrm{~mm}$ beam was $5.45 \mathrm{MPa}$ with the deflection value of $0.98 \mathrm{~mm}$. The increase in flexural strength of the $12 \mathrm{~mm}$ beam was about $35 \%$ than that of the $48 \mathrm{~mm}$ beam. The increase in deflection of the $12 \mathrm{~mm}$ beam was about $800 \%$ than that of the $48 \mathrm{~mm}$ beam. The results of $20 \mathrm{~mm}$ and $30 \mathrm{~mm}$ beams were in the middle range for the both flexural strength and deflection values. In contrast, the flexural strength of $6 \mathrm{~mm}$ beam was the minimum $(5.36 \mathrm{MPa})$. The deflection value $(4.71 \mathrm{~mm})$ was also well below than that of the $12 \mathrm{~mm}$ beam.

The flexural strength of 5 layers casting ( $10 \mathrm{~mm}$ each) beams was more $(7.41 \mathrm{MPa})$ than one-layer $(50 \mathrm{~mm})$ casting $(4.76 \mathrm{MPa})$ beams. The deflection value of the first $(4.2 \mathrm{~mm})$ was also more than that of second $(1.05 \mathrm{~mm})$. The increase in flexural strength and deflection were $36 \%$ and $410 \%$ respectively. The empirical model was developed for the both flexural strength and deflection values. The analytical curve fitted well with the experimental data for the beam thickness of not less than the length of the fiber. However, the problem was noted with the less thickness. The author recommends that it is better to produce the specimens not thinner than the length of fiber for HDM.

It concludes that the two-dimensional distribution of PVA fibers enhances the both flexural and deflection behavior of HDM. In practical application, it was made possible by producing the high flowable HDM.

\section{Acknowledgement}

The author carried out this research work in Maeda Corporation, Tokyo, Japan. All required expenditure required for this research work was funded by Maeda Corporation. The author would like to give sincere thanks to Dr. Matabee K. Maeda for his continued support during this research work. Sincere thanks also go to all counterparts who helped during the experimental work.

\section{Conflict of Interests}

The author declares that there is no conflict of interest regarding this publication.

\section{References}

1. Oh TK, Kim J, Lee C, Park S (2017) Nondestructive Concrete Strength Estimation based on Electro-Mechanical Impedance with Artificial Neural Network. Journal of Advanced Concrete Technology 15(3): 94102. 
2. Ozawa K (1989) Development of high-performance concrete based on the durability design of concrete structures. EASEC-2, 1: 445-450.

3. Ozawa K, Maekawa K, Okamura H (1992) Development of HighPerformance Concrete. Journal of the Faculty of Engineering, The University of Tokyo (B) XLI (3): 381-439.

4. Okamura H (1997) Self-compacting high-performance concrete. Concrete International 19(7): 50-54.

5. Wille K, Naaman AE, Parra MGJ (2010) Ultra high-performance concrete with compressive strength exceeding $150 \mathrm{MPa}$ : A simpler way. ACI Materials Journal 108(1): 46-54.

6. ACI 544 1R (1996) State-of-the-Art Report on Fiber Reinforced Concrete. American Concrete Institute, Farmington Hills, Michigan.

7. Barr BIG (1992) Fibre Reinforced Concrete-Where do we go from here? Fibre Reinforced Cement and Concrete. Proceedings of the fourth RILEM International Symposium, Edited by R. N. Swamy, E\&FN SPON, London, UK p. 3-11.

8. ACI Committee 6.44 (1982) State-of-the-Art Report on Fibre Reinforced Concrete. ACI 6.44. IR, ACI, Detroit, 9.

9. ACI Committee 6.44 (1993) Guide for Specifying, Proportioning, Mixing, Placing, and Finishing Steel Fibre Reinforced Concrete. ACI 6.44. 3R-93, ACI, Detroit.

10. Bartos PJM, Hoy CW (1996) Interaction of Particles in Fibre Reinforced Concrete. Proceedings of the International RILEM Conference on Production Methods and Workability of Concrete, edited by PJM. Bartos, DL Marrs \& DJ Cleland, E\&FN Spon, London, UK 461-462.

11. Hoy CW, Bartos PJM (1997) Mixing of Fibre Reinforced Concrete. Presented at the 1997 Spring Convention, American Concrete Institute, Seattle, Washington, U.S.A.

12. Hoy CW (1998) Mixing and Mix Proportioning of Fibre Reinforced Concrete. PhD Thesis, University of Paisley.

13. JCI-SF (1983) JCI Standards for Test Methods of Fibre Reinforced Concrete. Japan Concrete Institute (in Japanese).

14. Victor CL, Lin Z, Matsumoto T (1998) Influence of Fibre Bridging on Structural Size-Effect. International Journal of Solids and Structures 35 (31-32): 4223-4238.

15. Victor CL, Sun X, Wang S, Wu C (2001) Tensile Strain-Hardening Behaviour of Polyvinyl Alcohol Engineered Cementitious Composites (PVA-ECC). ACI material Journal 98 (6): 483-492.
16. Victor CL (2007) Engineered Cementitious Composites (ECC) Material, Structural, and Durability Performance. University of Michigan.

17. Kuraray (1993) Characteristics of KURALONTM (PVA fibre). Fibres and Industrial Materials Division.

18. Gong CX, Gong J, Zhang H (2008) Uni-axial Tension Behaviour of High Ductile Fibre Reinforced Cementitious Composite with Focus on Some Influencing Factors. Journal of Hydraulic Engineering 139(3): 361-366.

19. Pang CM, Leung CKY, Sun W (2009) Preparation and properties of high ductility cementitious composites with high content of fly-ash. Journal of the Chinese Ceramic Society 37(12): 2071-2077.

20. Li HD, Xu SL (2010) High Toughness Cementitious Composites Bending Properties and Toughness Evaluation Method. Civil Engineering Journal 3: 32-39.

21. Wang S, Le HTN, Po LH, Feng H, Zhang MH (2016) Resistance of HighPerformance Fibre-Reinforced Cement Composites against HighVelocity Projectile Impact. International Journal of Impact Engineering 95: 89-104

22. Zhang H, Liu Y, Sun H, Wu S (2016) Transient Dynamic Behaviour of Polypropylene Fibre Reinforced Mortar under Compressive Impact Loading. Construction and Building Materials 111: 30-42.

23. Gyawali TR (2018) Investigation on Dispersion and Mixing Method of PVA Fibres with Cement Paste. International Journal of Science and Research 7(3): 822-827.

24. Gyawali TR (2019) Investigation on Mixing Process for the Development of High Ductile Mortar Containing Thin and Short Fibres. International Journal of Materials Engineering 9(1): 8-15.

25. Gyawali TR (2019) Investigation on Performance of High Ductile Mortar with Different Sizes and Contents of Thin and Short Fibers. SN Applied Sciences 1(4).

26. Gyawali TR (2019) Investigation on Performance of High Ductile Mortar with Different Types of Sand and Mixing Process. SOJ Materials Science and Engineering, Symbiosis Group.

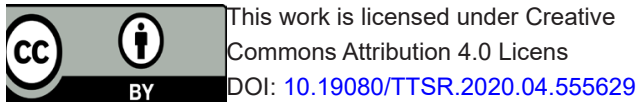

Your next submission with Juniper Publishers will reach you the below assets

- Quality Editorial service

- Swift Peer Review

- Reprints availability

- E-prints Service

- Manuscript Podcast for convenient understanding

- Global attainment for your research

- Manuscript accessibility in different formats

( Pdf, E-pub, Full Text, Audio)

- Unceasing customer service

Track the below URL for one-step submission https://juniperpublishers.com/online-submission.php 